\title{
HIGH SPEED FLOW VISUALISATION OF AN IMPINGING JET ON A PELTON TURBINE BUCKET
}

\author{
Alexandre Perrig, Mohamed Farhat, François Avellan* \\ Laboratory for Hydraulic Machines \\ Ecole Polytechnique Fédérale de Lausanne \\ Av. de Cour 33bis \\ 1007 Lausanne, Switzerland \\ Email: francois.avellan@epfl.ch
}

\begin{abstract}
This paper deals with flow investigations using endoscopes in a single-injector reduced scale Pelton turbine performed with a CMOS high-speed camera. Both onboard and external visualizations techniques of the flow in a bucket are presented. The flow observations evidence the unsteadiness of the successive steps of jet/bucket interaction, free surface flow development and evolution throughout the bucket duty cycle.
\end{abstract}

\section{NOMENCLATURE}

$B_{2} \quad$ Bucket width $[\mathrm{m}]$

$D_{1} \quad$ Jet pitch circle diameter $[\mathrm{m}]$

$D_{b} \quad$ Runner tip diameter $[m]$

$H \quad$ Test head $[\mathrm{m}]$

$Q \quad$ Discharge $\left[m^{3} s^{-1}\right]$

$z_{0} \quad$ Number of injectors [-]

$z_{b} \quad$ Number of buckets [-]

\section{INTRODUCTION}

The flow in Pelton turbines has not been analyzed so far with such details as the flow in the reaction turbines because the flow patterns and the hydraulic losses are very difficult to observe and quantify: the flow processes include jets, spray formation, free

\footnotetext{
*Address all correspondence to this author.
}

surfaces and film flows, secondary flows, and complex interaction between the components. A large population of droplets of various sizes stemming from the water sheets break-up, the jet dispersion, and the water sheets collision with the casing walls prevail around the runner, making the visibility poor. Moreover, features of interest are hidden between the buckets.

As a consequence few experimental visualizations of the flow in Pelton turbines were performed so far, and most of them in simplified configurations. Guilbaud et al. [1] investigated the flow in a simplified $2 D$ fixed bucket while Lowy [2] investigated particularly the interaction process of the jet by the bucket cutout in a fixed bucket. Bachman et al. [3] performed flow visualizations around a rotating Pelton runner with conventional lenses protected from the splashes by tubes and lighted by stroboscopes. To enable a close observation of the unsteadiness of the bucket flow, a innovative visualization technique using medical endoscopes bound to a high-speed CMOS camera has been developed. The results obtained from 2 approaches are presented: (i) visualizations of the relative flow in a bucket with an onboard endoscope and (ii) external visualizations of the absolute flow. The water film thickness in the bucket is determined by an image processing technique based on the refractive properties of air and water.

\section{VISUALIZATION TECHNIQUES}

The experimental investigations are performed for a singleinjector reduced scale Pelton turbine model. The specific en- 


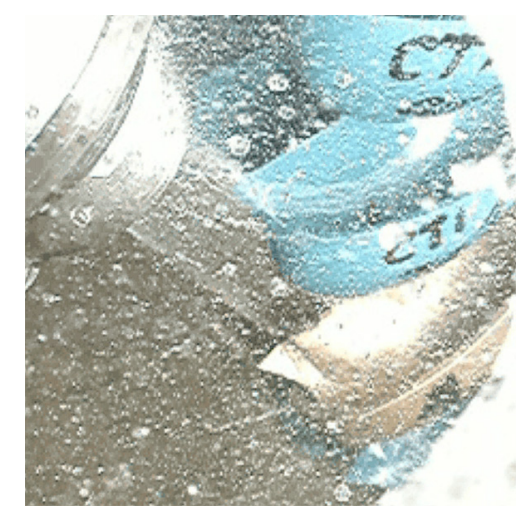

Figure 1. FLOW AROUND A PELTON RUNNER

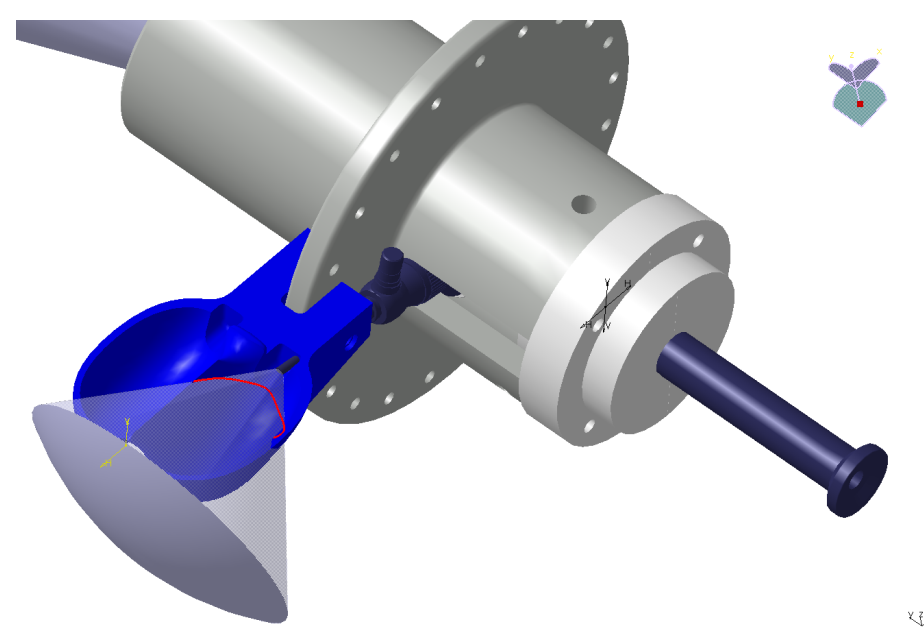

Figure 2. ENDOSCOPE ASSEMBLY

ergy is limited to $200 \mathrm{JKg}^{-1}$ (20 $\mathrm{m}$ head) to reduce the rotational speed and thus the centrifugal load on the distal lens of the onboard endoscope.

\section{ONBOARD SETUP}

A miniature endoscope, see Fig.2, is located at the root of the bucket to be instrumented, with the cone of vision covering half of the bucket. No water is to be expected there during normal operation, as Pelton's modification to Knight's original impulse turbine was precisely to avoid water flowing towards the flange [4]. Moreover, the mounting is non-intrusive and the field of observation is not obstructed by the splitter, while the radial acceleration prevents water droplets to stick on the distal lens of the endoscope. The CMOS camera head is kept outside the rotating parts of the test rig. The observation frames are transmitted via a $90^{\circ}$ optical deflector aligned with the runner rotation axis,
Table 1. EXPERIMENTAL CONDITIONS

\begin{tabular}{clll}
\hline $\begin{array}{c}\text { shutter } \\
\mu s\end{array}$ & $\begin{array}{l}\text { frame rate } \\
f p s\end{array}$ & $\begin{array}{l}\text { flash } \\
\text { ms }\end{array}$ & $\begin{array}{l}\text { resolution } \\
\text { pixels } \times \text { pixels }\end{array}$ \\
\hline 6 & 6000 & 6 & $512 \times 512$ \\
\hline
\end{tabular}

and protruding outside the test rig window. Therefore no data must be transferred through slip rings and no electronic component undergoes rotational forces. The flashlights are installed in waterproof housings that are mounted as close as achievable to the runner. An optical encoder sends a TTL signal via an adjustable delay line unit set to trig the camera and the flash units synchronously at the desired runner angular position. Even if the light source and camera capabilities allow measuring a complete bucket duty cycle, i.e. more than $90^{\circ}$, the non-moving assembly of the lighting system claims for a division of the duty cycle in overlapping subcycles to maintain adequate lighting conditions. Table 1 summarizes the experimental conditions.

\section{IMAGE PROCESSING}

The images captured by the onboard system have the drawback that the field of view rotates as the endoscope and the optical deflector rotate with the turbine rotor. A semi-automated process is set up to transform the raw images output by the camera into a sequence of images with a steady point of view.

\section{EXTERNAL SETUP}

The onboard observations are completed by a series of visualizations carried on in the absolute frame of reference using a large endoscope. The endoscope ocular is bound to the same CMOS camera mounted on a light tripod. The distal lens of the endoscope is fitted with a pneumatic wiping system.

\section{RESULTS}

The flow sequence of a bucket duty cycle is divided in 6 steps [3], [5]. The description of the flow sequences is performed according to Fig.4 and Fig.5.

(1) Approach of the tip to the jet. Beside appearing rippled, the jet surface exhibits perturbations and a series of convected impact craters. The convected craters are caused by the impact of large drops $(\simeq 3-5 \mathrm{~mm})$ stemming from condensation on the test rig walls or from the bounce of splashing water on the injector body.

(2) Initial feeding process. Once the tip and the cutout lips backside are in contact with the jet upper surface, the jet starts to separate in 2 branches, i.e. the upper one, that flows in the bucket inner surface, and the lower one that continues to feed 


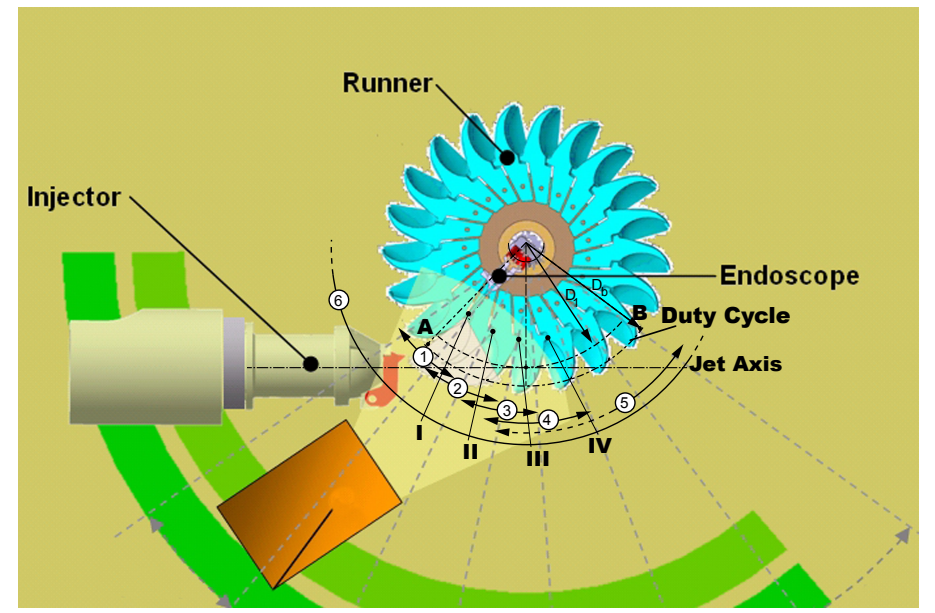

Figure 3. DUTY CYCLE DEFINITION
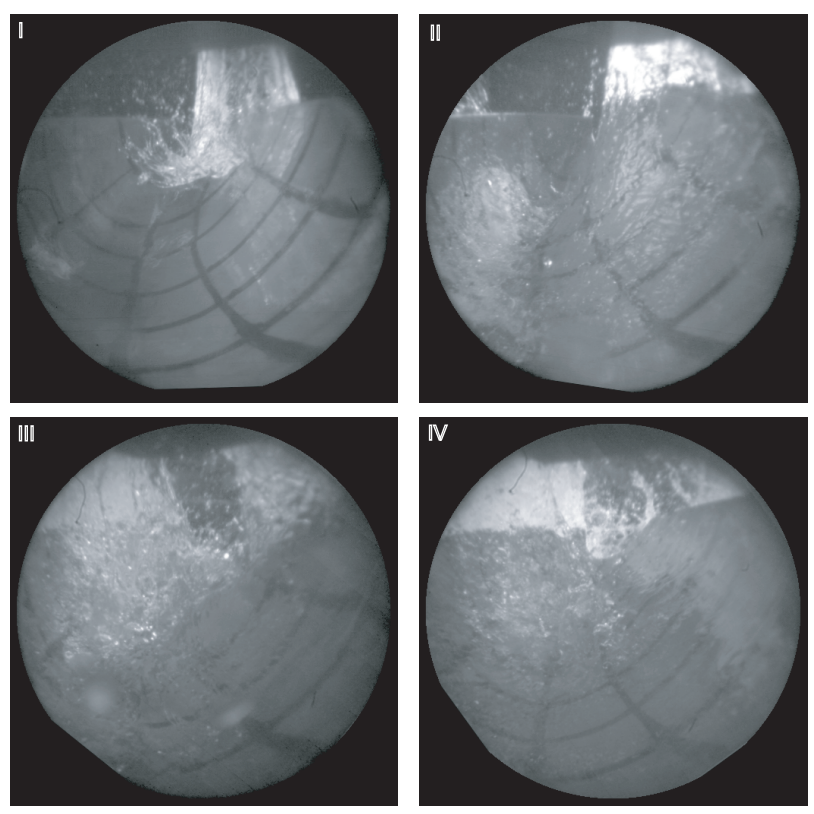

Figure 4. BUCKET ONBOARD FILM SEQUENCE

the next bucket. The image sequence show an outburst of the jet, and the appearance of a splay crown of water threads on the upper side. The jet front and the splay crown fly over the bucket and impinges on it later in the cycle. In fact, the cutout lips appears to act like a spillway [6]. Immediately after the impact, the onset of foam is clearly visible. At this point the jet is already partially cut by the next bucket. Thereafter, the flow evolves into the expected sheet flow moving first slightly towards the root and then laterally towards the outer edge.

(3) Entire separation of the jet. At this point the impinging main flow feeds the bucket mainly normally to the splitter. The separated portion of the jet remains attached to the bucket backsides far in the duty cycle, as predicted by Lowy [2] and observed by Bachmann [3]. In addition, it seems to be deflected against the bucket backside [5]. The deformations it displays match well the predictions made by Lowy [2]: the cross-section of the jet is crescent-shaped. The cross-section consists of 2 different flows: the core practically filled with liquid and the spray, which consists of numerous single separated water filaments.

(4) Last stage of inflow. The last threads and droplets of the distorted and disintegrated end of the jet enter the bucket partially on the bottom surface and partially on the lateral edges next to the cutout. Some of the water escapes the bucket directly through the cutout in a radial direction.

(5) Last stage of outflow. The water sheet presents a corrugated surface at the end as it not fed anymore. The outflow sheet remains fully developed late in the duty cycle, and becomes thinner and thinner until it breaks up, at first near the root and then towards the front.

(6) Series of droplets. The outflow never comes to an end. A line of droplets is visible along the entire runner periphery. The droplets are released from the outer edge tips, on the external side of the cutout, and from the splitter tip.

\section{CONCLUSION}

The flow observation techniques presented in this paper provide a good insight of the successive steps of the bucket duty cycle of a single-injector Pelton runner from the relative frame
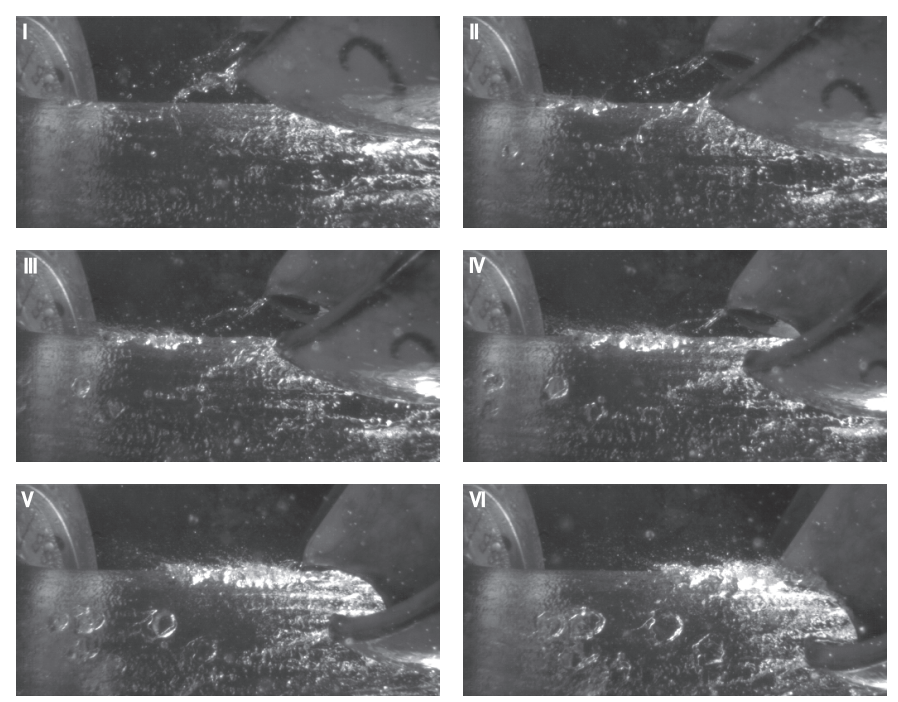
of reference. The unsteadiness of the free surface flow in the bucket is put into evidence. More details can be found in [7].

\section{ACKNOWLEDGMENT}

The authors would like to thank the staff members of EPFLLaboratory for Hydraulic Machines in Lausanne and of VATECH Hydro SA in Vevey for their dedication and enthusiastic support. This work is financially supported by the swiss promotion agency for innovation, KTI-CTI, Grant No. 6139.2, and VATECH Hydro SA.

\section{REFERENCES}

[1] Guibauld, M., Houdeline, J. B., and Philibert, R., 1992. "Study of the flow in the various sections of a pelton turbine". Proceedings of the $16^{\text {th }}$ IAHR Symposium, 14-18 September, pp. 819-831.

[2] Lowy, R., 1944. "Efficieny analysis of pelton wheels". Transactions of the ASME, 66, pp. 527-538.

[3] Bachman, P., Schrer, C., Staubli, T., and Vullioud, G., 1990. "Experimental flow studies on a 1-jet model pelton turbine". Proceedings of the $15^{\text {th }}$ IAHR Symposium, 11-14 September, pp. 1-13.

[4] Doble, W. A., 1899. "The tangential water-wheel". Transactions of the American Institute of Mining Engineers, California Meetting, 29, pp. 852-894.

[5] Perrig, A., Avellan, F., Kueny, J. L., Farhat, M., and E.Parkinson, 2006. "Flow in a pelton turbine bucket: $\mathrm{Nu}-$ merical and experimental investigations". Transactions of the ASME: Journal of Fluids Engineering, 128(4), pp. 350358.

[6] Chanson, H., 1996. "Air bubble entrainment in turbulent water jets discharging into the atmosphere". Transactions of the Australian Civil/Structural Engineering, CE39(1), pp. 3948.

[7] Perrig, A., 2007. "Hydrodynamics of the free surface flow in pelton turbine buckets". PhD thesis, École Polytechnique Fédérale de Lausanne. 